\title{
SAINT-Simon, SUPER-VAlistunUt REFORMIMIES
}

\author{
Arto Koho: VTT \\ arto.koho1@gmail.com \\ Janus vol. 27 (3) 2019, 316-325
}

Saint-Simon oli kuin ranskalainen Faust, joka kirjoitti laajoista aiheista ristiriitaisestikin. Katsauksessa painotetaan hänen seuraajiensa moninaista toimintaa, joka ulottui uskonnosta, kasvatuksesta, tieteestä ja taiteesta kaupunkien uudistamiseen ja paikallisista hankkeista kolonialistisiin. Saint-Simon ja saintsimonistit olivat super-valistuneita uudistusmielisiä.

\section{Positilvinen filosofia}

Ranskan vallankumouksen jälkeinen positiivishenkinen filosofia oli valistusfilosofian jatkoa. Valistuksen henki oli osin heikkenemässä. Teollisuuden nousu ja sosiaalisten ongelmien kärjistyminen nostivat kuitenkin odotuksia yhteiskuntatutkimusta kohtaan.

Claude-Henri de Saint-Simon (17601825) halusi uudistaa tieteitä, uskontoa ja yhteiskuntaa - näin laveassa kunniahimossa oli utopismin henkeä. Hän julisti 'positiivista filosofiaa' ihmisestä ja ihmisyhteisöstä. Yhteiskuntailmiöiden havainnointi ja tutkiminen oli saatettava tieteen piiriin, kilpailijaksi muiden tieteiden rinnalle. Auguste Comte (1798-1857) toimi jonkin aikaa Saint-Simonin sihteerinä ja muunsi hänen lavean tieteisuskonsa paremmin järjestetyksi kokonaisuudeksi. Positivismista tuli yksi tunnetuimmista filo- sofisista opeista, Comtesta sosiologian isä ja tieteen tutkimuksen uranuurtaja. Sosiologiaa on pidetty valistuksen lapsena ja valistusfilosofiaa ensimmäisenä modernina yhteiskuntatieteenä (Gronow 1996, 32). Saint-Simon oli tähän vähintäänkin osasyyllinen.

\section{SAINT-Simon ANTOI ALOITUSPOTKUJA}

1800-luvulla alkoivat nousevan tehdasteollisuuden rattaat jauhaa aiempaa voimallisemmin. Köyhien ja työläisten arjen ongelmista tuli pian myös tutkimuksen ongelmia. John Stuart Mill tunnusti, että politiikan tutkimuksessa oli otettava huomioon työväenluokan näkökulma. Aiheesta tuli suorastaan poliittinen uskontunnustus. Luokkien kesken on konflikteja, joten on tutkittava $\mathrm{mm}$. omaisuusinstituutiota. Saint-simonistit toivat Millin tietoisuuteen sosialismin kysymykset 1820ja 1830-lukujen taitteessa. (Mill 1879, 12-14; Mill 1873.)

Saint-Simon ehti monen uuden asian kimppuun ennen varsinaisia tiedemiehiä.Vuonna 1803 ilmestyi ensimmäinen pamfletti, jossa hän ehdotti älymystön ja paikallisten omistajien liittoa ihmisten kärsimyksen ja vallankumouksen kauhujen välttämiseksi (Saint-Simon 1975, Lettres d'un habitant de Genéve à ses contemporains). Tiedeuskosta tuli 
seuraavien kirjoitusten aihe. Tiede on edistynyt, joten teologian ja pappien tulee vastata sen haasteisiin. Tiedon ja uskomusten tulee kehittyä orgaanisessa suhteessa. Saint-Simon polemisoi: akatemiat ovat hallituksesta riippuvaisia. Hänen aikeensa olivat filantrooppisia ja voittivat akateemikoiden tarjoukset. Saint-Simon tukeutui Newtoniin ja katsoi, että fysiologia antaa kehittyessään välineet uudelle tieteelle. 18. vuosisata antoi meille Baconin, Locken, Newtonin ja ensyklopedistit. Tarvittiin uusi ensyklopedia. (Saint-Simon 1975, Introduction aux travaux scientifiques de XIXe siécle; Project d'encyclopédie.)

Inhimillinen ymmärrys oli kriisissä kaikkialla. Tiedemiesten oli otettava johtava rooli. Fysiologia ei ollut yltänyt asteelle, jonka tähtitieteet ja kemialliset tieteet olivat jo ohittaneet. Ihminen oli orgaaninen kokonaisuus - fysiologien tuli pukata filosofeja eteenpäin. Sosiaalisia suhteitakin tuli tarkastella orgaanisina kokonaisuuksina. Kriittisestä ja orgaanisesta tuli Saint-Simonin historiakäsityksen avainsanoja.

Hän lainasi yhteiskuntakäsityksensä matemaatikko Nicolas de Condorcet'lta (1743-1794), jonka mukaan tiede ja ihmisoikeudet ovat yhteydessä toisiinsa. Yhteiskunnan tulevaisuudesta voidaan esittää arvioita tieteen avulla. SaintSimon heräsi: yhteiskuntatieteestä tulee 19. vuosisadalla positiivinen tiede. Hän pyrki perustelemaan näkemyksensä tieteen kehityksen avulla (SaintSimon 1975, Extrait d'un ouvrage sur l'organisation sociale, 1804; Introduction aux Travaux Scientifiques du XIXe Siècle, 1807). Vuonna 1813 ilmestyi käsikirjoituskopioina Mémoire sur la Science de
l'Homme, jonka johdannossa mainitaan sanat 'philosophie positive'.

Nuori Augustin Thierry (1795-1856) oli Saint-Simonin sihteeri, ja he julkaisivat vuonna 1814 esseen eurooppalaisen yhteiskunnan uudistamisesta ja sellaisen poliittisen elimen luomisesta, joka takaisi erillisille kansakunnille itsenäisyyden. Tueksi tarvittiin yhtenäinen viisaiden hallinto. Tiedemiehet, opettajat ja papit edistäisivät yhteistä hyvää, ja uudistaminen tapahtuisi tiedeperusteisesti.

Saint-Simon siirtyi käsittelemään laajoja teollisuuden ja politiikan aiheita (L'Industrie, 1816-18; Système Industriel, 1821; Le Politique, 1819). Teollisuus voitaisiin nostaa kehityksen kärkeen paremmalla hallinnollisella kyvykkyydellä. Positiiviset tiedemiehet kuuluvat teollisuuspuolueeseen. Tiedemiehet hoitavat henkiset voimavarat, teollisuusmiehet aineelliset. Oli saarnattava uudistuksista, jotka vastaavat yhteistä etua ja suuren enemmistön intressejä (Saint-Simon 1975, 213 ja 225-226, Du système industriel, 1821).

Viimeinen julkaisu Nouveau Christianisme (1825) jäi kesken, vaikka SaintSimon oli puuhan mies. George Brandes sai aiheen sanoa, että Ranska osoitti kovin vähän mielenkiintoa Faustdraamaan, vaikka sieltä oli peräisin 1800-luvun Faust, joka oli väsymättömän intomielinen kaikkea tietoa kohtaan. Mathurin Dondo sai tästä idean teokselle The French Faust - Henri de Saint-Simon. Kaikkiruokainen SaintSimon oli sekä rationalisti että mystikko (Dondo 1955, 1). 
Saint-Simon oli ensimmäisiä Euroopan yhdentymiskehityksen puolestapuhujia ja rauhan puolustaja. Hän puhui suurelle yleisölle, koko ihmiskunnalle tai eurooppalaisille, joiden olisi hyvä ottaa onkeen viisaita neuvoja. Monet aikalaiset pitivät häntä suuruudenhulluna.

\section{SAINT-SIMONISTIT PANIVAT TOIMEKSI}

On vaikea sanoa, mikä Saint-Simonin teksteissä on täsmällisesti hänen omaansa. Keith Taylor jätti pois kokoamistaan Saint-Simonin teoksista mm. L'Industrie'n kolmannen ja neljännen osan tekstejä sekä 8. ja 9. kirjeen tekstit L'Organisateurista, koska ne ovat Comten laatimia. Comte oli myös saavana osapuolena ja peri SaintSimonilta kolme ideaa: historiallisen kehityksen (kriittinen ja orgaaninen vaihe), teollisen yhteiskunnan ja henkisten voimavarojen ideat. Saint-Simon ymmärsi tieteen suuren merkityksen uudenaikaiselle yhteiskunnalle. (Bourdeau 2018, 6.)

Saint-Simonin kirjoitukset jäivät usein huomiotta. Monet seuraajien julkaisut syntyivät luentojen yhteydessä ja saivat laajempaa huomiota. Liike alkoi sosiaalifilosofian pohdintoina ja päätyi mystiseen uskontoon.Vuodesta 1830 lähtien liike sai kovan sysäyksen, joten se ei ollut enää vain muutaman intellektuellin piiri. Monet uudet yhteiskunnalliset ideat olivat peräisin saint-simonisteilta vuosien 1820-1850 välillä erilaisen liikehdinnän purkautuessa esiin Euroopassa. Louis Blancinkin mielestä näyttämö oli heidän hallussaan. (Wittman 2010, 25; Brick 2011, 4). Richard Wittmanin (2010, 25-31) mukaan oli arvokasta, että saint-simonistit kiinnos- tuivat asutun ympäristön ja kaupunkien tilasta, jopa arkkitehtuurista. Heistä tuli super-valistuneita uudistajia oppiisänsä rinnalle.

Saint-Simonilla oli loistavia sihteereitä, $\mathrm{mm}$. Augustin Thierry, Auguste Comte, Léon Halévy sekä Olinde Rodrigues. Opin propagoijia ja sen perusteiden tulkkeja olivat mm. Saint-Amand Bazard (1791-1832) ja Prosper Enfantin (1796-1864). Doctrine de Saint-Simon ilmestyi 1828-1929 Bazardin ja Ėmile Barraultin (1799-1869) toimittamana. Hippolyte Carnot (1801-1880) ja Bazard julkaisivat seuraavana vuonna toisen yhteenvedon luennoista ja keskusteluista.

Enfantin oli piirin toinen päätekijä, joka liikkui laajoilla aihealueilla ja käsitteli mm. poliittista taloustiedettä, uskontoa ja filosofiaa. Carnot oli mukana Le Producteur -lehden toimituksessa ja saarnasi opista eri puolilla Eurooppaa. Hänestä tuli joksikin aikaa opetusministeri (1848) ja kansalliskokousedustaja. Muita saint-simonistien kansalliskokousedustajia olivat mm. Èmile Barrault ja Michel Chevalier (1806-1879).

Augustin Thierry jätti joukot ja kääntyi historian pariin. Pierre Leroux (17971871) kehitti erottuaan omaa humanismin oppia (Individualisme et socialisme). Jokainen yksilö on humaanisuuden vapaan puun hedelmä. Olemme vastuussa toisillemme ja vastavuoroinen hyvän tekeminen on velvollisuus. Hallitusvalta ei sytytä kaikkia valoja eikä ohjaa kaikkea moraaliamme. Mutta hallitusvalta ei saa olla kykenemätön sytyttämään valoja eikä ohjaamaan moraalia (Leroux 1834, 10-13). Leroux'n romanttis-symbolisella käsitteistöllä on avunsa: 
sosiaalista elämää voidaan tarkastella avoimena vuorovaikutuksellisena kokonaisuutena (Breckham 2013, 21-22). Kolmas eroaja oli Philippe Buchez (1796-1865), joka kehitti omaa kristillistä sosialismia ja julkaisi teoksen tieteen ja humanismin historiasta (1833). Comten veroisia ei heistä tullut.

\section{LEHDET SYNNYTTIVÄT LIIKKEEN}

Liikkeen aikakauskirjoja olivat L'Industrie (1816-1818), Le Politique (1818-1819) ja L'Organisateur (18191820). Syntyi myös L'Organisateur Belge, joka ilmestyi puolen vuoden ajan.Vuosina 1820-1822 Saint-Simon ja Comte julkaisivat kolme aikakauskirjaa nimellä Du Système Industriel. Catéchisme des Industriels ilmestyi 1823-1824. Sitä edelsi itsemurhayritys. (Booth 1871, 124; Töttö 1996, 85.)

Le Producteur ilmestyi vuonna 18251826 Enfantinin ja Olinde Rodriguesin (1795-1851) johdolla. Saint-Simonin kuoleman jälkeen ilmestyi Le Globe, jota kriitikko Charles Augustin SainteBeuve (1804-1869) ja Pierre Leroux toimittivat vuodesta 1929 lähtien. Se oli liberaalien ja romantikkojen vahva äänitorvi. Vähitellen siitä tuli saint-simonistien tärkein julkaisu, joka ilmestyi päivälehtenä. Leroux erosi vuonna 1831 toimituksesta. Tammikuussa 1832 sotilaat keskeyttivät toiminnan, oikeudenkäynnit alkoivat ja Le Globe lakkasi ilmestymästä jo huhtikuussa. (Locke 1986, 9 ja 92-93.)

Enfantin oli hyvin kiinnostunut Benthamista. Myös Bazard oli Benthamin tuntija ja ranskansi vuonna 1828 Benthamin teoksen Defence of Usury
(1788). Suhde Benthamiin ei ole yksiselitteinen. Bazard näki hänet myönteisessä valossa. Benthamin suurimman onnen periaate ja saint-simonistien "suurimman ja köyhimmän luokan moraalisen ja fyysisen tilan parantaminen", kuten se Le Globessa visiona esitettiin, nähtiin toisiaan vastaaviksi. Myöhemmin Benthamia alettiin pitää "kylmän järjen taloustieteilijänä" ja jopa laisser-faire'n edustajana. (Booth 1871, 100; Bellett 2011,21-25.) Pieleen meni myöhempi tulkinta - Bentham tähdensi yhteiskunnan ohjaamista lainsäädännön ja hallinnon keinoin, kuten saint-simonistit itsekin.

Saint-simonistien lehdistö oli vapaan kaupan kannattaja.Vielä toisen tasavallan aikana Enfantin ja Charles Duveyrier (1803-1866) perustivat Le Crédit -nimisen talouslehden, joka ilmestyi lyhyen aikaa (1848-1850). (Booth 1871, IV; Iggers 1954, 37.)

\section{UUSI KRISTINUSKO JA SOSIAALIREFORMIT}

Oma kirkko perustettiin vuonna 1829. Enfantin ja Bazard olivat "ylimmät isät" ja liike siirtyi uskonnon suuntaan. Uskonnosta ja feminismistä tuli liikkeen kohtalonkysymyksiä. Enfantin kannatti vapaan rakkauden oppia, Bazard ei. Seurasi välirikko ja vuoden 1831 lopulla Enfantin oli yksin "isä". Liike alkoi hajota ja kadotti rahoittajia. (Iggers 1954, 34-36.)

Uskonnollinen vaikutus oli aluksi melkoinen. Erillisiä kirkkokuntia syntyi Toulouseen, Montpellieriin, Lyoniin, Dijouniin, Metziin ja Limogesiin. Lontoossakin oli kaksi uskonnollista yhteisöä, joita kutsuttiin "tieteellisiksi kir- 
koiksi”. (Booth 1871,VII ja 125.) Kun super-valistuksen liike muuttui uskonnolliseksi, kannattajille suunniteltiin yhtenäinen sininen vaatetus. "Isä" ("Le Pére") vahvisti uskonnollista hurmosta ja seremoniallisuutta. Enfantin isännöi lähellä Pariisia Ménilmontantin tilaa, jossa kannattajat kävivät opissa. Toimintaan kuului työtä, kokouksia, ulkoilmajuhlia, harjoituksia, pelejä, kuorolaulua ja tarinointia.

Saint-simonistien kansanopetus eteni siten, että ensin pidettiin luento ja seuraavia askelia olivat yhdentyminen (assosiaatio) ja keskustelu. Joillakin luennoilla Pariisin Rue Taiteboute'lla oli yli tuhat osallistujaa ja luentoja saattoi olla useita viikossa. Lopuksi mentiin illanviettoon Monsigny'lle. (Locke 1986, 76-77; Booth 1871, 110-119.)

"Uuden kristinuskon" mukaan yhteiskunta tuli järjestää niin, että siitä koituu suurin mahdollinen hyöty suurimmalle joukolle. Saint-Simon pohjusti tämän vahvasti: Jumala on antanut periaatteen ohjenuoraksi ihmiselle (Saint-Simon 1975, 289). Uskontoon - ja sosiaalifilosofiaan - liittyi utilitaristinen vire. Saint-Simon oli enemmän suurimman onnen edistäjä eli suunnitteluun ja kasvatukseen uskova sosiaalipoliitikko kuin etujen tasoitukseen pyrkivä sosialisti. Talousopin tärkein osa oli kysymys omaisuudesta. Doctrine (1829, 214-249) sisältää jakson omaisuuden teorioista. Omaisuus on perimyksen kautta tai kyvykkyydellä hankittua. Omaisuudet, myös perityt, tulee saattaa yhteiskuntaa hyödyttävään käyttöön. Kyvyt ovat lahja, jota tulee hyödyntää ja teollisuutta edistää kaikin tavoin.
Saint-Simon oli kiinnostunut naisten vapautuksesta, mutta ei tehnyt siitä suurta numeroa. Hänen seuraajansa olivat tässä asiassa innokkaampia vaatien vapaata rakkautta tai rauhallisemmin äänenpainoin avioeron tekemistä helpommaksi (Taylor 1975, 50). Saintsimonistien suunnitelmissa voidaan nähdä korporatiivisen yhteiskunnan tai hyvinvointiyhteiskunnan esimuoto. Liike oli edellä monia aikansa aatesuuntia ja toi esille radikaaleja yhteiskunnallisia aiheita. Luokka-analyysina se oli naiivi, mutta innosti sekä käytännön miehiä että taiteilijoita. (Locke 1986, 10.)

Mutta ei niin hyvää, ettei jotakin pahaa. Intoa olojen ja sivistyksen kehittämiseksi riitti Afrikkaan asti. Ranska oli miehittänyt osia Algeriasta vuonna 1830. Se kohtasi kovaa vastarintaa, mutta siirtomaavalta kesti aina vuoteen 1962 saakka. Sen ensimmäisinä vuosikymmeninä jopa 825000 algerialaisen arvioidaan kuolleen yhteenotoissa.

Osama Abi-Mershedin mukaan "modernin apostolien" työ joutui ongelmiin. Enfantin ja Thomas Urbain (1812-1884) olivat modernisointiajatusten takana. Urbainista tuli myöhemmin Louis Napoléon Bonaparten neuvonantaja. Hänellä oli ristiriitainen rooli: yhtälttä hän ymmärsi alkuperäisyhteisöjä ja kritisoi kolonisaatiota ("Algeria kuuluu algerialaisille"), toisaalta hän edisti Arab Bureaux'n virkamiehenä arabikuningaskunnan perustamista. Koulutus oli kontrolloidun assosiaation keino. Pian ideat himmenivät ja päädyttiin normaaliin ranskalaiseen hallintoon ja sotilashallintoon. Arab Bureaux yritti säädellä alkuperäisyhteisön kehitystä muttei kyennyt estämään konflikteja (Abi-Mershed 2010, 11-12 
ja 92). Idealismi haalistui kolonialismin ristipaineissa.

\section{LIIKENTEEN JA KAUPUNKIEN UUDISTAMINEN}

Ferdinand de Lesseps'n (1805-1894) kerrotaan osallistuneen saint-simonistien luennoille ja saaneen innostuksen Suezin kanaalihankkeelle. Aloitteen oli tehnyt Egyptissä käynyt Enfantin. Vuonna 1846 koottiin kansainvälinen valtuuskunta, jossa Enfantin edusti Ranskan hallitusta. Enfantin oli takapiruna myös rautateitä uudistettaessa. Höyryveturiliikenne alkoi kehkeytyä 1830-luvulla ja rautatieverkko laajeni.

Ranskan infrastruktuurihankkeiden tueksi luotiin Crédit Mobilier vuonna 1852. Se oli Émile Pereiren (18001875) ja Isaac Pereiren (1806-1880) luomus. He olivat merkittäviä finanssimiehiä ja "Creditistä" tuli vahva sijoitustoimija suurille hankkeille. Veljekset olivat nuoruudessaan saint-simonisteja.

Arkkitehti Jean-Louis Viel de SaintMaux oli julkaissut teoksen Lettres sur l'architecture des anciens et celle des modernes (1787), ja Èmile Barrault tarttui siihen vuonna 1830. Kriittisten kehitysvaiheiden arkkitehtuuri oli kuin Baabelin tornien rakentamista ja ilmensi erilaisia uskomuksia. Orgaanisen kehitysvaiheen rakennukset ilmentävät yhteisiä uskomuksia. (Wittman 2010, 31-32.)

Barrault oli alkujaan retoriikan professori Collège Sorèze'sta ja vastasi usein taidelinjauksista. Le Globessa tuettiin kaupunkisuunnittelua ja siirtymää moderniin. Charles Duveyrier laati kirjoi- tussarjan tulevaisuuden Pariisista, joka jakautuisi neljän päätien erottamiin sektoreihin. (Wittman 2010, 34-35; Locke 1986, 45-52). Kaupunkisuunnittelussa tuli huolehtia myös hygieniasta ja vesihuollosta. Pariisissa puhkesi keväällä 1832 koleraepidemia. Lontoossa benthamilaiset toimivat samaan aikaan hygieniaolojen ja terveydenhuollon uudistajina Edwin Chadwickin johdolla.

Charles Louis Napoléon Bonaparte (1808-1873) sai Sainte-Beuvelta nimen "Saint-Simon hevosen selässä". Hänen pamflettinsa Köyhyyden poistaminen (1844) rakentui kahdelle ajatukselle: maa on hyödynnettävä ja työ organisoitava paremmin. Otettuaan vallan Napoleon III ryhtyi uudistamaan Pariisia, muita Ranskan kaupunkeja ja rautateitä. Valtion tehtäviin kuului myös köyhimmän luokan aseman parantaminen, mutta kansallisten työkeskusten kokeilut eivät olleet onnekkaita. Onnekkaammin sujui valtion lainoitus- ja tukitoiminta pankkien ja luottoyhtiöiden avulla. (Guérard 1943, 193-218.)

\section{TAIDE ON YhTEISKUnNALlista}

Saint-simonistit tunnistivat ensimmäisten joukossa taiteen yhteiskunnallisen luonteen. Käsitys oli käytännöllis-painotteinen, utilitaristinen tai sosiologinen. Taiteilijoiden oli katsottava ympärilleen ja elettävä veljeyden hengessä. Saint-Simonin käsitykset taiteesta eivät ilmeisesti olleet erityisen syvällisiä. L'Organisateurissa hän suri sitä, että taiteista on tullut ylellisyystuotteita ja toivoi, että järjestettäisiin sytyttäviä julkisia juhlia. (Locke 1986, 15-32.) 
Taiteilijalle asetettiin yhteiskunnallinen haaste: taiteilija on aikansa profeetta. Ranskan kirjallisuudessa saint-simonistien vaikutus on liitetty muutosvaiheeseen, jossa romantiikka väistyi realismin tieltä. Filosofeista ja kirjailijoista saintsimonistien sympatisoijiksi on mainittu Maxime du Camp, Charles Renouvier, Ernest Renan, Georg Sand, SainteBeuve, De Lamennais ja Pierre-Jean de Béranger.

Saint-Simon tapasi Pariisissa jo vuonna 1802 sosiaalifilosofiasta kiinnostuneen Mme de Staelin ja vieraili hänen salongissaan. Pariisiin syntyi lukuisia kirjallisuus- tai taidesalonkeja. Saint-simonistit painostivat sivulta: taiteilijoiden tuli avautua yhteiskunnan suuntaan. Pierre Leroux'lla oli läheiset suhteet mm.Victor Hugoon ja George Sandiin. (Taylor 1975, 19-20; Locke 1986, 299; Iggers $1958,2)$. Realismi eteni kuvataiteissakin. Mielenkiintoisella tavalla taiteen realismi, yhteiskunnalliset liikkeet ja yhteiskuntatieteet kehittyivät rinnakkain.

Tuija Vertainen yhdisti Saint-Simonin sosiaalisen kysymyksen esilletuloon. Kirjailijat puuttuivat köyhyyteen, kurjuuteen ja sosiaalisiin ongelmiin paljon ennen kuin viranomaiset ehtivät reagoida. Vertainen viittasi myös Georg Sandin (1804-1876) Lélian (1833) arviointiin, mistä vastasi Sainte-Beuve. Teoksessa käsiteltiin ensi kertaa naisen omaa seksuaalisuutta pelkoineen ja kaipuineen (Vertainen 1998, 50 ja 60-61).

Varsinaisia saint-simonistien taidekoulukuntia ei syntynyt. Vaikutus tunnustettiin ja niin on jälkikäteen muisteltu. Filosofi Charles Renouvier (18151904) "heräsi" opiskeltuaan Mont- pellierin École polytechnique'ssa, kuten monet saint-simonistit. Jarkko S. Tuusvuoren mukaan Renouvier jakoi 1800-luvun ranskalaisfilosofian restauraation (vallankumouksen vastareaktio), konsiliaation (sovittautuminen rakenteisiin) ja saint-simonismin henkeen. Jako on altis kritiikille ja se unohtaa $\mathrm{mm}$. henkisten liikkeiden sisäiset jännitteet (Tuusvuori 2002, 9). Henkilökohtaisen vaikutuksen arvioinnissa oma muistelu on toki luotettavin todistus.

Saksasta sympatisoijiin on liitetty Heinrich Heine (1797-1856) ja Lorenz von Stein (1815-1890). Heine muutti vuonna 1831 Pariisiin ja eli siellä pitkään. Hän oli tärkein saint-simonistien ajatuksia Saksassa esille tuonut kirjailija. Muita kannattajia olivat Ludwig Börne, Heinrich Laube (sosiaalisen kysymys ja uskonto kuuluvat yhteen), Karl Schall ja Karl Gutzkow. Kirjailijoiden innostus jäi vähäiseksi, vaikka ikääntyneen Goethen sanotaan lukeneen säännöllisesti Le Globea. Filosofeista sympatisoijiksi on mainittu Eduard Gans ja Karl Ludwig Michelet. (Gerathewohl 1920, 13-32; Iggers 1958, 33; Lichtheim 1983, 62.) Lorenz von Stein kunnostautui Ranskan yhteiskunnallisten liikkeiden analysoijana ja tunnetuksi tekijänä. Hän kiinnitti huomiota, Ranskan esimerkin valossa, yhteiskunnallisen eriarvoisuuden kasvuun (Grimmer-Solem 2003, 109).

Pietarissa Alexander Herzen (18121870) ja muutama muu nuori intellektuelli saivat vieraakseen saint-simonisteja vuonna 1829. Herzen ja Nikolai Ogarev (1813-1877) ylläpitivät 1830ja 1840-luvuilla kirjallista piiriä. Myös nk. Petrashevskyn ryhmä tutki saint- 
simonistien ideoita. Dostojevski oli mukana vuonna 1848 ja sai virikkeitä näkemykselle sosialismista uutena uskontona. (Lichtheim 1983, 119-130; Taylor 1975, 53.)

Myös musiikki on yhteiskunnallista. Marseljeesin sanat sovitettiin teollisuuden edistämiseen verta tihkuvien taistelujen sijasta. Marseljeesin sanoittaja ja säveltäjä Claude Joseph Rouget de Lisle (1760-1836) teki laulun Premier Chant des industriels, jonka Saint-Simon julkaisi vuonna 1821 kommentein $D u$ systéme industrielsissa (Locke 1986, 3334).

Musiikin taitajista innokkaita saintsimonilaisia olivat Felicien David, Jules Vincard ja Dominique Tajan-Rogé. Sympatiaa ovat osoittaneet Liszt, Berlioz, Mendelssohn, Nourrit, Hiller, Halévy ja Henri Reber. Felicien David (1810-1876) oli köyhä orpo, joka jo nuorena liittyi saint-simonisteihin. Egyptin retkestä vuonna 1832 tuli hänelle löytöretki. Ohjelmasinfonia Autiomaa (Le Désert, 1844) on Veijo Murtomäen mukaan aikansa tärkeimpiä ranskalaisteoksia ja eksotiikan ensimmäisiä ilmentymiä. Se sisältää arabialaisia sävelmiä ja puhuttua tekstiä. Sinfonia Christophe Colombo (1847) sisältää myös eksoottisia, "villien" tansseja ja lauluja. David sävelsi hymnin Saint-Simonille (1832) ja hänen musiikkiaan käytettiin "seuroissa". Fromental Halèvy (17991826), Léonin veli, oli oopperoiden ja kuoroteosten säveltäjä. Hän laati oppaan koulujen musiikkikasvatusta varten ja edisti kuoroliikettä. (Murtomäki 2006, 1; Locke 1986, 3 ja 81-97.)

\section{ONKO ARVOA ANNETTU?}

Sosiologit ovat väheksyneet Saint-Simonia, vaikka ideanikkarin ansiot on myönnetty. Émile Durkheim (18581917) antoi hänelle tunnustuksen sekä positivismin että sosiologian perustajana (postuumi Le Socialisme, 1928). Pertti Töttö on noteerannut Saint-Simonin Comten edeltäjänä ja uudistusmielisenä hallinnon ideoijana (Töttö 1996, 83-87). Politiikan tutkijoiden on ehkä ollut helpompi tunnistaa Saint-Simonin merkitys. Alan Ryan on pitänyt häntä poliittisen sosiologian isänä, tosin "kastamattomana" (Ryan 2012, 649).

Saint-Simonissa nähtiin totalitarismin hengenheimolainen. Näin häntä arvioivat jo Friedrich A. Hayek ja Hannah Arendt. Georg G. Iggers (1958) kokosi väitöskirjaansa tätä näkökantaa tukevan mittavan aineiston erityisesti saintsimonistien lehdistöstä. Syypää ei ollut niinkään Saint-Simon, vaan inspiroituneet seuraajat. Saint-Simon ei kannattanut kaikkivoipaa valtiota, mutta hänen näkemyksissään on autoritaarisia piirteitä. (Iggers 1958, 7; Taylor 1975, 37). Usko ideoiden mahtiin antoi aiheen syytteille teknokraattisuudesta ja totalitaarisuudesta.

Myönteisemmälle tulkinnalle on perusteita. Alan Ryanin mielestä SaintSimonilla oli kaksi loistavaa sosiaalisen muutoksen ideaa: tieteelliset ideat ja järkevä hallinto. Hän ymmärsi oikeastaan ensimmäisenä teollisuusyhteiskunnan merkityksen - "Industriel regime" voittaa "feudal regimen" (Ryan 2012, 647-650). 
Saint-Simon oli monessa asiassa 'välittäjä'. Moren Utopian (1516) perinne siirtyi saint-simonisteilta sosialistien piiriin. Francois Chateaubriand oli elvyttänyt uskontoa (Génie du christianisme, 1802), mistä Saint-Simon innostui. Sosiologista linjaa loivat Comte, Durkheim ja Weber (Picon 2003, 1-14).

Jälkikäteen hyvän tekijä nähdään usein kaikkialla ja aikaansaannoksia yliarvioidaan. Saint-Simon ei yltänyt suureksi tiedemieheksi. Super-valistus, reformimieli ja yhteiskuntatieteiden edistäminen ovat silti kestäviä ansioita, vaikka seuraajien elävä liike katosi varsin pian.

\section{KirjallisuUs}

Abi-Mershed, Osama (2010) Apostles of Modernity: Saint-Simonians and the Civilizing Mission in Algeria. Stanford: Stanford University Press. https://archive.org/stream/ (Luettu 26.6.2019)

Bellett, Michel (2011) Saint-Simonism and Utilitarianism: The History of a Paradox. Bentham's Defence of Usury under Saint-Amand Bazard's Interpretation. https://halshs.archives-ouvertes.fr/ halshs-00654847 (Luettu 26.6.209)

Booth, Arthur John (1871) Saint-Simon and Saint-Simonism: A Chapter in the History of Socialism in France. London: Longmans, Green, Reader and Dyer.

Bourdeau, Michel (2018) Auguste Comte, Stanford Encyclopedia of Philosophy, 1-27. https://plato.stanford.edu/entries/ comte (Luettu 26.6.2019)

Bowle, John (1966) Politics and Opinion in the 19th Century. London: Jonathan Cape.

Breckham, Warren (2013) Adventures of the Symbolic Post-Marxism and Democratic Theory. New York: Columbia University Press.

Brick, Michael (2011) The Proffered Pen: Saint-Simonianism and the Public Sphere in 19th Century France. University of Oregon. https://core.ac.uk/ download/pdf/36685962.pdf (Luettu 26.6.2019)

Doctrine de Saint-Simon: première année (1829) (Library of University of Lausanne).

Dondo, Mathurin (1955) The French Faust - Henri de Saint-Simon. New York: Philosophical Library.

Gerathewohl, Fritz (1920) St.Simonistische Ideen in der deutschen Literatur - Ein Beitrag zur Vorgeschichte des Sozialismus. München: G. Birk \& Co. https:// archive.org/details/stsiministischei00gerauoft (Luettu 26.6.2019)

Grimmer-Solem, Erik (2003) The Rise of Historical Economics and Social Reform in Germany 1864-1894. Oxford: Oxford University Press.

Gronow, Jukka (1996): Valistusfilosofia ja poliittinen taloustiede: yhteiskuntatiede omalakisena järjestelmänä. Teoksessa Jukka Gronow, Arto Noro \& Pertti Töttö (toim.) Sosiologian klassikot. Helsinki: Gaudeamus, 31-60.

Guérard, Albert (1943) Napoleon III. Cambridge: Harvard University Press.

Hewett, Gaspar (2008) Henri de Saint-Simon. Notes written for Progress of the Human Mind: From Enlightenment to Postmodernism. http://www.thegreatdebate.org.uk/Saint-Simon.html (Luettu 26.6.2019)

Iggers, Georg G. (1958) The Cult of Authority. The Political Philosophy of the Saint-Simonians. A Chapter in the Intellectual History of Totalitarianism. The Hague: Martinus Nijhoff.

Leroux, Pierre (2018) Individualism and Socialism, and Other Writings on the Doctrine of Humanity. The Libertarian Labyrinth. http://library.libertarianlabyrinth.org/items/show/3138 (Luettu 26.6.2019)

Lichtheim, George (1983) A Short History of Socialism. London: Fontana Paperbacks.

Locke, Ralph P. (1986) Music, Musicians and the Saint-Simonians. Chicago \& London: University of Chicago Press.

Mill, John Stuart (1879) Socialism. Chicago: Belfords, Clarke \& Co. www.gutenberg.org/files/38138/38138-h/38138h.htm (Luettu 26.6.2019)

Mill, John Stuart (1873) Autobiogra- 
phy. www.gutenberg.org/cache/epub/10378-images.hmtl (Luettu 26.6.2019)

Murtomäki, Veijo (2006) Romanttinen ranskalaissinfonia. Muhi - Musiikinhistoriaa verkossa. http://www.siba.fi/muhi

Picon, Antoine (2003) Utopian Socialism and Social Science. In Cambridge History of Science. Teoksessa Theodore M. Porter \& Dorothy Ross (toim.) Volume 7: The Modern Social Sciences. Cambridge: Cambridge University Press, 7182. http://nrs.harvard.edu/urn-3:HUL. InstRepos:23853805 (Luettu 26.6.2019)

Ryan, Alan (2012) On Politics - A History of Political Thought from Herodotos to the Present. London: Penguin Books.
Saint-Simon, Henri (1975) Selected Writings on Science, Industry and Social Organisation. Toim. Keith Taylor. London: Croom Helm.

Tuusvuori, Jarkko S. (2002) Ranskan filosofinen 1800-luku. Niin \& näin (2), 8-14.

Töttö, Pertti (1996) Auguste Comte - positivismin isä. Teoksessa Jukka Gronow, Arto Noro \& Pertti Töttö (toim.) Sosiologian klassikot. Helsinki: Gaudeamus, 61-88.

Vertainen, Tuija (1998) Ranskan kirjallisuuden historia - Esiromantiikasta postmoderniin. Helsinki: Finn Lectura.

Wittman, Richard (2010) Space, Networks and the Saint-Simonians. Grey Room 40 (Summer 2010), 24-49. 